\title{
The Usefulness of Different Types of Health Research: Perspectives from a low-income country
}

\author{
Burchett, H. E. D., Mayhew, S. H., Lavis, J. N., Dobrow, M. J.
}

\begin{abstract}
:
This article explores the perceived value of public health research and the types of research considered useful in Ghana. Sixty-nine decision makers, researchers and stakeholders were interviewed. A broad range of research was highly valued. Two traits were important: an applied, relevant topic and quickly produced findings. Interviewees valued research which explored implementation issues or identified and increased understanding of health problems. Effectiveness research often lacked these traits and was not generally considered as important because it was implicitly assumed that as long as interventions (that were based on a good understanding of the situation) were implemented well, they would be effective.
\end{abstract}

\section{Background}

In recent decades there has been increasing interest in encouraging the use of research in health policy and practice (Klein, 2003, Black, 2001). Although initiated in clinical medicine in high-income countries, attention and effort has spread to public health policy and systems, as well as to low-income countries (Siddiqi and Newell, 2005, Anderson et al., 2005, Kemm, 2006).

Evidence-based medicine focuses almost exclusively on 'what works'. This is reflected in an established hierarchy of evidence that prioritises effectiveness research, with randomised controlled trials (RCTs) and systematic reviews of RCTs considered to be the gold standard (McGuire, 2005). With this prioritisation definitions of effectiveness have narrowed in focus to the exclusion of other study designs that may have previously been considered acceptable (Victora et al., 2004, Kirkwood et al., 1997). 
In the late 1990s, an awareness of the 'lack' of research use in low-income countries led to calls for efforts to encourage the use of evidence-informed approaches (Garner et al., 1998, Dans et al., 1998). Following the pattern seen in high-income countries, the focus was initially on the use of medical research, with public health policy and systems research use following later (McMichael et al., 2005). Despite this, there has been little exploration of how effectiveness research and other types of research, is valued in low-income countries - though this can influence the use of research by decision makers.

This article focuses on the perceived value of research and the types of research considered useful for maternal health policy and practice, as well as broader public health decision-making in Ghana. It represents one element of a larger study which aimed to explore perceptions of the usefulness of research for public health decisionmaking in Ghana (Burchett, 2010, Burchett et al., 2012a, Burchett et al., 2012b, Burchett et al., 2012c). The objectives for the part of the study reported here were:

1. To understand the value placed on research, or the perceived importance of research use in decision-making

2. To explore the extent to which research is perceived to be used

3. To identify the types of research considered useful, or used, in decision-making

4. To assess whether perceptions vary depending on the type of researcher or decision-maker

Ghana is a low-income country in West Africa that is considered to be one of the more stable and developed in the region. Despite development indicators higher than most sub-Saharan African countries, it has been unable to reduce its maternal mortality ratio in recent decades (Ghana Statistical Service (GSS) et al., 2009, World Health Organization, 2010). Maternal health was chosen as a case study topic through which research use issues would be explored since it exhibits many of the characteristics of public health which make research use difficult. For example maternal health interventions are often large, complex and context-sensitive and at 
present the maternal health evidence base is insufficient and contestable (Burchett and Mayhew, 2009).

\section{Methods}

Data were collected through semi-structured interviews. National and sub-national government decision-makers, researchers and other stakeholders working in the field of maternal health in Ghana were sampled purposively. National and subnational government staff were approached if their work remit included maternal health, even if they were not specifically focused on the topic. Sub-national staff were interviewed in one urban and one rural region. Stakeholders were included if their work specifically covered maternal health or, if there were no staff with such a focus in the organization, those with a broader health remit. Some interviewees were identified from the Reproductive Health Policy and Standards document, which included a list of participants involved in its development (Ghana Health Service (GHS), 2007). Others were identified through publications and from discussions with interviewees and with colleagues at both the London School of Hygiene \& Tropical Medicine (LSHTM) and the Ghana Health Service (GHS) Health Research Unit. Interviews were conducted by HB and were usually 45-60 minutes long (ranging from 20 minutes to 80 minutes). The interview schedule was adapted for each type of interviewee so that national and sub-national government staff, researchers and stakeholders were all asked questions relevant to their own work. It was flexible enough to be altered during interviews, depending on interviewees' time constraints or their knowledge and expertise, as gleaned during or prior to the interview. The interview schedule also included probes to encourage clarification of meanings and further discussion of emergent issues of interest.

Most interviews commenced with a discussion of the interviewee's role and employment background. Researchers were asked about the maternal health research they had been involved in, including whether they felt it had been used. Government staff and stakeholders were asked about their own use of research, whether they'd been involved in any research studies and their perceptions of the 
usefulness and use of research for themselves and others. Definitions of research and 'research use' were not provided in the interviews; interviewees' own perceptions of the terms were followed.

The first four interviews were intended to be pilots, in that the interview schedule was amended after each (and then again, after preliminary analysis of the first fifteen interview transcripts). However since changes were not substantive and data from these initial interviews remained relevant, three of these were included in the final analysis. The fourth interviewee was excluded from analysis because, although based in Ghana, they did not work in the country.

The interviews were recorded unless permission to record was refused by the interviewee. In two such cases, as well as a third when equipment failed, notes were taken during the interview and typed up in more detail immediately afterwards. Recorded interviews were transcribed verbatim. Framework Analysis was used to analyse the interview data and 'Atlas.ti' software was used to manage the data. This method of analysis was chosen because it allowed the identification of key themes arising from the data whilst also providing the opportunity to explore pertinent issues identified a priori (Ritchie and Spencer, 1994). The coding framework was devised by first analysing a subset of interview transcripts $(n=5)$ to identify broad codes emerging from the data. These were then cross-checked with the objectives of the study to ensure they were all covered by the identified codes; additional codes were added as necessary. The coding framework was then applied to all of the transcripts. The coding framework was devised by HB, in discussion with SM. All the coding was completed by HB.

Ethical approval was gained from the London School of Hygiene \& Tropical Medicine and the Health Research Unit of the Ghana Health Service (GHS). Interviewees were given an information sheet describing the study and were asked to sign a consent form before participating. 


\section{Findings}

\section{Description of sample}

In total, 67 interviews with 69 interviewees were conducted between February 2008 and March 2009 in Ghana and England (on two occasions interviewees invited a colleague to participate in the interview with them). In total, 25 government staff, 18 stakeholders (e.g. World Health Organisation, non-governmental organisations (NGO) and development partner or donor staff), 24 researchers and two others, who had conducted research and also held government positions (either currently or previously) participated.

There were a range of research producers: working in universities in Ghana and overseas, in the health research centres of the GHS, as well as those who conducted research as a secondary activity to their main role. This latter group included health service managers and NGO staff, some of whom conducted small scale research in their own organisation to inform their own work and/or were involved in large international research studies. Table 1 categorises the 69 interviewees included in the study. Most of the sample was Ghanaian, with the exception of six Europeans, two North Americans and two interviewees from other West African countries.

Table 1: Types of interviewees

\begin{tabular}{|l|r|}
\hline \multicolumn{1}{|c|}{ Type of interviewees } & Number \\
\hline National government staff & 13 \\
\hline Sub-national government staff & 12 \\
\hline National/international agencies & 14 \\
\hline Development partner staff & 4 \\
\hline University researchers & 15 \\
\hline Ghana Health Service (GHS) researchers & 9 \\
\hline Other & 2 \\
\hline Total & 69 \\
\hline
\end{tabular}




\section{Definitions of Research}

The concept of research was broad for many interviewees, incorporating not only formal studies but also routine data, government reports or even informally talking to people. Some conceptualised research as something that is applied, whose inherent purpose is to improve health or health services; others explained that it included anything that is done to understand a situation.

"So for me research is not just the normal research that we know, the academic way of doing it, I mean, the administrative way of looking at it is also good. It's research, it helps and as a programme manager I am always looking out for those opportunity, yes, I mean, to use those as a basis, you know, for coming up with interventions, yes. And also even to reassure me that whatever interventions you are putting in place are okay, they are right."

032, national government staff

Whilst some acknowledged that routine data may not be considered 'research', many implicitly incorporated it into their conceptualisation, referring to its usefulness when asked about research.

"... we keep trying to improve the routine data systems. So that is one part of research because you are monitoring."

059, national government staff

'Operations research' (and operational studies - the terms were used interchangeably) was a frequently mentioned type of research, although the meaning ascribed to the phrase was quite different to the formal mathematical methodologies it traditionally refers to. Definitions of operations research were often vague, but some used the term to refer to any study that was 'applied' or relevant to policy or programming, whilst for others it described small, qualitative or 'informal' studies. 
"when you say operational studies, it's basically studies to answer...questions that we have as part of our work. As we do our work, questions [arise], so if it requires a qualitative study to do that, we do it...if....we need to do an intervention study, we do it. So I wouldn't say one type of study. I'd put all of that into an operational. Anything that will answer the questions because we do not do research for doing's sake"

064, sub-national government staff

Although recognised as different to academic research, operations research was conducted by all types of research producer in Ghana, both non-academic (e.g. hospital doctors and sub-national health service staff) and academic."[and can I just ask you what you mean by operations research?] oh, policy-oriented research...It's different from academic work, when you're writing academic paper, you have to argue from a theoretical perspective and all those stuff, you know. Policy-makers are not interested in that. What is the problem? How did you do it? What are your findings? What suggestions do you make for addressing this problem, that's operational research."

047, academic researcher

\section{Research Traits Valued}

There were two key traits that were associated with the perceived usefulness of research: the relevance of the topic and the speed with which findings were generated.

Research that was applied and was directly relevant to their own programmes or current health problems under their jurisdiction was, understandably, highly valued. 
"[what does research mean to you?] finding out what is going on and bringing out recommendations and solutions so that we can change for better. Because you see you just can't do, go and look at things and say that you are just doing research for research's sake. You should, you should improve the system."

030, national government staff

Interviewees often distinguished between 'big' research, which they considered to be formal, large scale and theoretical, and 'small' research, which they considered to have more direct relevance to health service delivery or programmatic issues. It was not only smaller scale but also quicker and with less rigorous methods than its comparator. Operations research was one example of small research. Conversely, big research was not always considered necessary. Big research studies typically focused on evaluating the effectiveness of new interventions or policies that had yet to be accepted or implemented on a wide scale in Ghana. They lacked the immediate, practical relevance of 'small' research.

"[When people talk about research, what does that mean to you?] Well there's research with a large " $R$ " and research with a small " $r$ ". I think Ghana Health Service does have a programme but supported by Dutch [funding]. It's a research programme with a small $r$, it's more operational research and it's done mostly by research institutions here in Ghana, not just Ghana Health Services but also District Health Teams or Regional Health Teams or individual people. And then there's the, the large research that you would really, well, set up, large research - some questions and test some theories"

010, stakeholder

How research was funded, and who conducted it, affected who set the research agenda. Big research tended to be funded externally by international or foreign organisations and generally involved non-Ghanaian collaborators. They would often 
set the research agenda. The lack of Ghanaian input in determining the focus of such research often affected the perceived relevance of the findings.

"But you see most of the time what happens is that...London School of Hygiene and Tropical Medicine has an idea and then they come [to Ghana]...and it's done and they say it's a seven country study, so even if Ghana doesn't need it, Burkina will need it, you know? So those are the things, because we are really not funding our own research we also have very little role in initiating, the research question."

011, national government staff

By contrast, small research was often unfunded, with the agenda set by the person who would conduct the research alongside their main role, such as a health service manager. This would often also be the person who would then be in a position to use the findings directly in their work. In having complete control over the research agenda, they were able to study issues of current importance to them in their daily work and were in a position to act directly on the findings.

"I don't need a big research, I just need to go and talk to the community people and once I get those results, I will use that to improve and make sure people come to the facilities. So those are the minor operational research that, for me, at this stage, are very useful."

036, sub-national government staff

"So even using your own service data you would be able to give you a sense of direction ... our service data indicate that between 20 to 30 percent of our maternal mortality all across Ghana are due to complications of unsafe abortion. So if you are able to recognise that from your service data then you don't have to wait for any publication to come from anywhere to say that reducing the incidence of unsafe abortion is likely going to improve maternal health in, in your area. So using your mere operations research service data are 
little, little ways that people can use to generate evidence to push forward national policies."

040, sub-national government staff

The lack of national research funding, and the implications this had for an internallydetermined national research agenda, were noted.

“The problem is that the government doesn't fund research so while some of the people in the Ministry will want us to address specific questions, they don't have resources to call the shots"

051, university researcher

Not all types of research fitted neatly into one category. For example the Demographic and Health surveys were a highly valued form of research. These surveys were large-scale, involving external financial support and foreign collaborators, with much of the research agenda set at the global level. As such, they might have been conceptualised as 'big' research. However they lacked a theoretical approach and allowed some national input into the questions asked. They were also considered to be relatively applied. As such, they manifested important traits of 'small' research and were a highly valued form of research.

Despite the simplicity of the concepts, the terms 'big' and 'small' research were nevertheless used by many of the interviewees and they highlight the key attributes of research that were valued, namely focusing on a pertinent, applied topic with speedy completion which allowed the immediate application of results.

\section{What Was Research Useful For?}

National and sub-national government staff felt that research use in policy and practice was very important and it was becoming an increasingly explicit ideal. 
A range of types of research were considered to be useful for decision-making. Some explicitly noted that different types of research would be of use to different types of research users (e.g. policy-makers and health professionals), or to answer different types of questions, such as what strategic objectives to set, how to achieve these objectives or how to assess and improve implementation.

Interviewees particularly valued research exploring implementation and research that identified problems and helped to understand them. Research to evaluate effectiveness was not generally considered to be as important.

\section{Research to explore implementation}

Interviewees often described the importance of research to assess the implementation of policies, programmes or health services, in order to identify bottlenecks or challenges which could then be addressed. Operations research was one form of research cited as looking at health service delivery problems or programme implementation issues. Other types of research that were noted by a range of interviewees as helping to explore implementation included routine data, national surveys (e.g. Demographic and Health surveys) and Master of Public Health student theses. Routine data were recognised as being a useful means of monitoring existing policies and programmes.

"[research is] extremely useful in the sense that I look at it, particularly operational research...operational research means you, you observe as you are running programmes. You observe a bottle neck and you want to find answers to it. Immediately to inform you to change, probably your course of action, to be able to improve the system better."

036, sub-national government staff

Research to identify and understand health problems

Operations research and other 'small' research studies, as well as routine data, were also valued because they provided information about the nature of health problems. 
Interviewees explained that solutions or interventions could be devised once there was a clear understanding of the cause of the problem or who was affected.

"[okay and so how useful do you find research is for you in your work?] it's useful and it's important because if you want to deal with an issue you must understand the issue and not just tackle it with the assumptions you have. Because your assumptions may all be flawed in which case you would use your time and resources and not achieve anything significant. So it, it's good to try to understand the situation and we, I find it useful...sometimes it's just by talking to people working on the job you'd get an understanding of the situation or just looking at the data and asking you can come out and kind of identify the issues and then deal with it. So even though it's, I'll say it that is not, may not be very, I mean formal and organised research with a protocol et cetera et cetera, at least, you want to find why things are working or why things are not working and then you try to understand and make the necessary corrections."

060, sub-national government staff

Some also explicitly noted the importance of qualitative research for understanding contextual dimensions of health problems or providing explanations for quantitative findings.

"So I prefer researches that are not just giving numbers but reasons behind the numbers and the actions... before we develop any strategy for any programme, we do some research and what we have found is that many a time we need to do...qualitative research to understand issues, so it will help us to develop our strategies and our messages and materials."

045, national government staff

National surveys, such as the Demographic and Health Surveys, were clearly valued by a range of interviewees as a means of defining the size or importance of health problems. Interviewees appreciated them not only because they provided information about the current status of various health problems but also because 
they could be used to identify trends over time. Routine data were also recognised as helping to identify health problems.

\section{Research to evaluate effectiveness}

Research which assessed the effectiveness of policy and programme was generally perceived to be of less direct importance to decision-making. Interviewees tended to feel that 'effective' policies and programmes could be designed once there was a thorough understanding of the situation (as could be gathered through 'small' research which defined the problem). This is illustrated in the quote below:

"what we have found is that many a time we need to do...qualitative research to understand issues, so it will help us to develop our strategies and our messages and materials."

045 , national government staff

There were two main explanations for why effectiveness research was not considered useful to interviewees. Firstly, there was an implicit assumption that as long as interventions (that were based on a good understanding of the situation) were implemented well (as could be ascertained through operations research and monitoring with routine data), they would be effective. The need for effectiveness research was therefore not obvious. The quote below highlights the prioritisation of research focusing on implementation ("how you get it done") over effectiveness research.

"I think the most useful for us is normally the operational researches that we, yeah, at this level those ones are very important. When we look at the systems and we need to know what is going wrong and how we can better the system, we, we do operational researches, yes."

065, sub-national government staff

"...research is very important to us and when there is anything and we want it to be evidence-based we'll be looking for money but we don't wait for the 
money to do a big time research. Sometimes you can do something small...Everybody wants big, big research with numbers and statistical significance but you don't need statistical significance to save a life...everybody knows that these things work but how you get it done, you know?"

059, national government staff

Secondly, the location of effectiveness research, in terms not only of agenda setting (as discussed above) but also its use, may have been felt to be at a global, or at least a non-Ghanaian, level. Effectiveness research was more likely to be big research and, as such, have an externally-driven research agenda as well as other traits that may make it less appealing, as discussed above. Some interviewees gave examples where effectiveness research had been used at an international level, such as by the World Health Organisation, where it influenced policies that were then adopted within Ghana. In such cases the research use had therefore taken place at a higher level; there was no need for such studies to be replicated in Ghana. These tended to be examples of research on the efficacy or effectiveness of discrete interventions, such as a medical product.

"there's been research [in other countries] on intermittent preventive treatment in infants already. And they, found out that it reduces morbidity and mortality among infants. So research have proven this so now, what UNICEF did was that they got money from the Gates Foundation to try and see if they could operationalise this idea within the health system. Because you know the way research is done it's not the same as the normal routine system. So what happens is we worked with the whole of the [region] here, this research was not to prove whether IPTI works or does not work. But we were just trying to learn lessons from how that can be operationalised in the normal routine services and what are the problems that will come up. Will the health system be able to cope with such an additional activity? What are the difficulties involved? How much more will it cost the health system to deliver the IPTI? So it was like a programme but an operations research, yeah." 


\begin{abstract}
"[this policy is about] cost-effective interventions which are known, which have been tested, I mean we are not going to test it again, that they are known, the efficacy is already there, if you are testing it probably in terms of strategies and other things"
\end{abstract}

058, national government staff

As the quotes above illustrate, a number of interviewees did mention the need to study policies and programmes. However they tended to refer to monitoring whether or not the policy was being implemented as planned, or whether it was perceived to be acceptable and effective, rather than attempting to assess its effectiveness through a more rigorous intervention evaluation.

\title{
Differences between types of interviewees
}

A striking finding that emerged from the interviews was the homogeneity of views regarding the usefulness and use of research. It might have been expected that academic researchers expressed greater appreciation of effectiveness research and other academic research, whilst non-academics cited a preference for small research. However no great division in opinion was found. This may be because researchers and decision-makers were not restricted to one narrow area of work. For example, academic researchers in Ghana conducted both big and small research, and so were able to appreciate that big, academic research was not necessarily of use to decision-makers, who preferred small research. Involvement in big research was not limited to academics: some non-academic researchers, as well as national and sub-national government staff had been involved in international, academic research studies. There was also movement between research and decision-maker roles; those conducting research did not limit their careers to such work but moved into NGO or government positions and vice versa. These overlaps in both research 
experience and work experience may therefore explain the lack of diversity of views, since the sample was more homogenous than current job titles alone suggested.

\section{Discussion}

Conceptualisations of research were broad. It was clear that research beyond the narrow, academic definition was highly valued for use in policy in Ghana. The value of these broader forms of research has been recognised in the research use literature. Lomas et al. noted that outside the research community, broad definitions of 'evidence' prevail (Lomas et al., 2005). Despite awareness that academic research alone is not sufficient to inform decisions and that other informal research, routine data, monitoring and experience are needed, much of the literature on evidence-informed public health policy and systems remains firmly focused on the narrower, academic definition of research (Kohatsu et al., 2004; Pablos-Mendez and Shademani, 2006). However the debate around broadening the evidence base for public health policy and systems (compared to evidence for evidence-based medicine) revolves mainly around the importance of including a wider range of academic disciplines and methods (such as qualitative research) rather than the consideration of non-academic research (Kohatsu et al., 2004; Anderson et al., 2005; Mays et al., 2005; Davies et al., 2008).

Evaluations of effectiveness were not perceived to be a high priority for public health decisions in Ghana. This may be because such evaluations tend to focus on assessing potential policy or programme options that could be adopted in future, whereas the decision-makers interviewed were focused on the more immediate realities of identifying current problems and improving existing policies and programmes by addressing implementation challenges. Policies were assumed to be effective as long as they were based on a clear understanding of the nature of the problem and were implemented properly. This explains the emphasis on 'small' operations research in order to understand health problems and to address problems experienced during the implementation of policies and programmes. Interviewees in this study 
particularly valued research that focused on current implementation challenges or identifying and understanding health problems. Other studies in low-income countries have found a similar preference for operations research, routine data and surveillance, as well as smaller, less rigorous studies in public health (Tomson et al., 2005, Behague et al., 2009, Woelk et al., 2009).

Supporting the findings from the current study, it is becoming increasingly recognised that those making decisions around public health policy and systems issues need answers to questions other than merely 'what works'. There have been arguments in the academic literature that RCTs and traditional systematic reviews of effectiveness may not be the most appropriate methods to use in public health policy and systems because they do not answer all of the questions a decision-maker may ask (Frommer and Rychetnik, 2003, Cookson, 2005, Kemm, 2006). Instead it is recognised that different types of research studies may answer different types of questions (Hanney et al., 2002, Mays et al., 2005, Lavis, 2009; Lomas et al., 2005; Sheldon, 2005). For example, RCTs do not answer questions about how an intervention works, or in which contexts it is effective (Davies et al., 2000, Cookson, 2005). There has been substantial work into the design, analysis and reporting of studies, for example the incorporation of contextual and other intervention data into RCTs (Campbell et al., 2004, Eldridge et al., 2008, Kirkwood et al., 1997, Rychetnik et al., 2002, Hawe et al., 2004). There have also been some efforts in recent years to offer guidance on how other forms of evidence (beyond effectiveness research) can be identified, synthesised and used in policy-making (Oxman et al., 2009, Mays et al., 2005, Lomas et al., 2005).

However despite these efforts, the evidence-informed public health movement remains largely focused on encouraging the use of evaluations of the effectiveness of interventions. Methodological debate has tended to focus on how interventions can or should be evaluated, rather than what types of evidence may be considered most useful by decision-makers (Sanson-Fisher et al., 2007, Pablos-Mendez and Shademani, 2006, Kohatsu et al., 2004, Rychetnik et al., 2004, Waters, 2009, Glasgow et al., 2006). 
There is now some understanding of the importance of both contextual, academic research (i.e. beyond efficacy or effectiveness research) and local information, yet there appears to have been little acknowledgement of 'small' research in the public health literature (Lomas et al., 2005, Lambert, 2006). However this may be slowly changing, with operations research promoted by the World Health Organization and high-profile journals such as the Lancet (as a sub-category of health policy and systems research) (Bennett et al., 2008a, Bennett et al., 2008b, Mills et al., 2008). Nevertheless at present in low-income countries, funds and support for such research remain relatively limited at the national and sub-national levels.

Although the value of a range of types of research and a variety of research producers have been noted previously in the literature, the evidence-informed public health movement remains largely focused on 'big' research (Lomas et al., 2005, Kohatsu et al., 2004, Pablos-Mendez and Shademani, 2006). Such research tends to lack the traits found to be valued in the current study, notably speedy completion and a focus on an applied topic of current pertinence.

A higher-order issue relates to the funding of research and setting of research agendas. The international competitive nature of academic research funding, and the fact that low-income countries often lack the capacity to compete against northern institutions for funding, mean that those in-country are rarely able to set their own 'big' research agendas. Until low-income countries are able to set their own research agendas, or influence the research agendas of those conducting big (externallyfunded) research, they are likely to continue to prefer small studies, as they themselves will have been able to choose which topics to focus on to ensure that they have direct relevance to their current concerns.

\section{Strengths and limitations of this study}

There has been little exploration of the issue of research use in policy from the perspective of researchers and decision-makers in low-income countries; the current 
study attempted to address this gap. However it is limited by the fact that it focused only on one country, Ghana, and one policy topic, maternal health. The lack of importance placed on evaluation may be specific to maternal health interventions, which tend to be complex and difficult to evaluate. Nevertheless, this could be argued for many aspects of public health policy and systems. The study is also limited in that it only explored perceptions of the usefulness and use of research and did not attempt to assess actual research use or impact. The issues explored in this study are concerns in many low-income countries and so the findings may be relevant elsewhere; further research could confirm or confute this.

\section{Conclusion}

In summary, although this study found that there was acceptance of the need for research use in policy and practice, the preference for small research focused on current issues highlights a major disconnect with focus of the international evidenceinformed public health movement, namely effectiveness research focused on potential interventions. The research attributes that were particularly valued were speedy completion and the ability to set the research agenda to ensure a focus on practical issues to address immediate challenges. Interviewees valued research which explored implementation issues or which identified and increased understanding of health problems. Those aiming to encourage research use in Ghana should attempt to understand the perspectives of decision-makers (i.e. potential research users), to recognise the role of non-academic research producers and appreciate the value of a broader range of research types.

\section{References}

ANDERSON, L. M., BROWNSON, R. C., FULLILOVE, M. T., TEUTSCH, S. M., NOVICK, L. F., FIELDING, J. \& LAND, G. H. 2005. Evidence-Based Public Health Policy and Practice: Promises and limits. American Journal of Preventive Medicine, 28, 226-30. 
ANDERSON LM, PETTICREW M, REHFUESS E, ARMSTRONG R, UEFFING E, BAKER P, FRANCIS D, TUGWELL P., Using Logic Models to Capture Complexity in Systematic Reviews. Research Synthesis Methods, 2011. 2: p. $33-42$.

ARAI, L., ROEN, K., ROBERTS, H. \& AL., E. 2005. It Might Work in Oklahoma But Will It Work In Oakhampton? Context and implementation in the effectiveness literature on domestic smoke detectors. Injury Prevention, 11, 148 - 151.

BEHAGUE, D., TAWIAH, C., ROSATO, M., SOME, T. \& MORRISON, J. 2009. Evidence-Based Policy-Making: The implications of globally-applicable research for context-specific problem-solving in developing countries. Social Science and Medicine, 69, 1539 - 1546.

BENNETT, S., ADAM, T., ZAROWSKY, C., TANGCHAROENSATHIEN, V., RANSON, K., EVANS, T., MILLS, A. \& ALLIANCE STAC 2008a. From Mexico to Mali: Progress in health policy and systems research. The Lancet, 372, $1571-1578$.

BENNETT, S., OXMAN, A. \& HAINES, A. 2008b. Prospects for Health-Systems Research. The Lancet, 371, 1913.

BLACK, N. 2001. Evidence Based Policy: Proceed with care. British Medical Journal, $323,275-9$.

BURCHETT, H. E. D. 2010. Perceptions of the Usefulness of Public Health Research for Policy in Ghana. PhD, University of London.

BURCHETT, H. E. D., LAVIS, J. N., MAYHEW, S. H. \& DOBROW, M. J. $2012 a$. Perceptions of the Usefulness and Use of Research Conducted in Other Countries. Evidence \& Policy, 8, 7-16.

BURCHETT, H. E. D. \& MAYHEW, S. H. 2009. Maternal Mortality in Low-Income Countries: What interventions have been evaluated and how should the evidence base be developed further? International Journal of Gynecology and Obstetrics, 105, 78 - 81.

BURCHETT, H. E. D., MAYHEW, S. H., LAVIS, J. N. \& DOBROW, M. J. 2012b. The applicability and transferability of public health research from one setting to another: A survey of maternal health researchers Global Health Promotion, in press.

BURCHETT, H. E. D., MAYHEW, S. H., LAVIS, J. N. \& DOBROW, M. J. $2012 \mathrm{c}$. When can research from one setting be useful in another? Understanding perceptions of the applicability and transferability of research. Health Promotion International. 
CAMPBELL, M. K., ELBOURNE, D. R., ALTMAN, D. G. \& FOR THE CONSORT GROUP 2004. CONSORT Statement: Extension to cluster randomised trials. British Medical Journal, 328, 702 - 708.

COOKSON, R. 2005. Evidence-Based Policy Making in Health Care: What it is and what it isn't. Journal of Health Services Research and Policy, 10, 118-21.

DANS, A. L., DANS, L. F., GUYATT, G. H. \& RICHARDSON, S. 1998. Users' Guide to the Medical Literature XIV: How to Decide on the Applicability of Clinical Trial Results to your Patient. Journal of the American Medical Association, 279, 545-549.

DAVIES, H., NUTLEY, S. \& SMITH, P. 2000. Introducing Evidence-Based Policy and Practice in Public Services. In: DAVIES, H. T. O., NUTLEY, S. M. \& SMITH, P. C. (eds.) What Works? Evidence-Based Policy and Practice in Public Services. Bristol: The Policy Press.

DAVIES, H., NUTLEY, S. \& WALTER, I. 2008. Why 'Knowledge Transfer' is Misconceived for Applied Social Research. Journal of Health Services Research and Policy, 13, 188-90.

ELDRIDGE, S., ASHBY, D., BENNETT, C., WAKELIN, M. \& FEDER, G. 2008. Internal and External Validity of Cluster Randomised Trials: Systematic review of recent trials. British Medical Journal, 336, 876 - 880.

FROMMER, M. \& RYCHETNIK, L. 2003. From Evidence-Based Medicine to Evidence-Based Public Health. In: LIN, V. \& GIBSON, B. (eds.) EvidenceBased Health Policy: Problems and possibilities. Oxford: Oxford University press.

GARNER, P., KALE, R., DICKSON, R., DANS, T. \& SALINAS, R. 1998. Implementing Research Findings in Developing Countries. British Medical Journal, 317, 531 - 535.

GHANA HEALTH SERVICE (GHS) 2007. Reproductive Health Strategic Plan 2007 2011. In: REPRODUCTIVE AND CHILD HEALTH DEPARTMENT (ed.). Accra, Ghana: GHS,.

GHANA-NETHERLANDS HEALTH RESEARCH FOR DEVELOPMENT PROGRAMME. Reports and Publications [Online]. Available: http://www.partnership-programmes.org/hrp/html/reports.htm [Accessed 22nd April, 2010.

GHANA STATISTICAL SERVICE (GSS), GHANA HEALTH SERVICE (GHS) \& MACRO INTERNATIONAL 2009. Ghana Maternal Health Survey 2007. Calverton, Maryland: Macro International. 
GLASGOW, R. E., KLESGES, L. M., DZEWALTOWSKI, D. A., ESTABROOKS, P. A. \& VOGT, T. M. 2006. Evaluating the Impact of Health Promotion Programs: Using the RE-AIM Framework to Form Summary Measures for Decision Making Involving Complex Issues. Health Education Research, 21, 688 - 694.

HANNEY, S. R., GONZALEZ-BLOCK, M. A., BUXTON, M. \& KOGAN, M. 2002. The Utilization of Health Research in Policy-Making: Concepts, examples, and methods of assessment. HERG Research Report No.28. Uxbridge, Middx UK: Brunel University.

HAWE, P., SHIELL, A., RILEY, T. \& AL., E. 2004. Methods for Exploring Implementation Variation and Local Context within a Cluster Randomised Community Intervention Trial Journal of Epidemiology and Community Health, 58,788 - 793.

KEMM, J. 2006. The Limitations of 'Evidence-Based' Public Health. Journal of Evaluation in Clinical Practice, 12, 319-324.

KIRKWOOD, B. R., COUSENS, S. N., VICTORA, C. G. \& DE ZOYSA, I. 1997. Issues in the Design and Interpretation of Studies to Evaluate the Impact of Community-Based Interventions. Tropical Medicine and International Health, 2, 1022-1029.

KLEIN, R. 2003. Evidence and Policy: Interpreting the Delphic oracle. Journal of the Royal Society of Medicine, 96, 429-31.

KOHATSU, N. D., ROBINSON, J. G. \& TORNER, J. C. 2004. Evidence-Based Public Health: An evolving concept. American Journal of Preventive Medicine, 27, 417 - 421.

LAMBERT, H. 2006. Accounting for EBM: Notions of evidence in medicine. Social Science and Medicine, 62, 2633 - 2645.

LOMAS, J., CULYER, T., MCCUTCHEON, C., MCAULEY, L. \& LAW, S. 2005. Conceptualizing and Combining Evidence for Health System Guidance. Ottowa: Canadian Health Services Research Foundation.

LOOI, M.-K. 2009. Feature: Platform for Research - African Institutions Initiative [Online]. London: The Wellcome Trust. Available: http://www.wellcome.ac.uk/News/2009/Features/WTX055738.htm [Accessed 20th February 2010.

MAYS, N., POPE, C. \& POPAY, J. 2005. Systematically Reviewing Qualitative and Quantitative Evidence to Inform Management and Policy-Making in the Health Field. Journal of Health Services Research and Policy, 10, 6 - 20.

MCGUIRE, W. L. 2005. Beyond EBM - New directions for evidence-based public heath Perspectives in Biology and Medicine, 48, 557-569. 
MCMICHAEL, C., WATERS, E. \& VOLMINK, J. 2005. Evidence-Based Public Health: What does it offer developing countries? Journal of Public Health, 27, $215-221$.

MILLS, A., GILSON, L., HANSON, K., PALMER, N. \& LAGARDE, M. 2008. What Do We Mean by Rigorous Health-Systems Research? The Lancet, 372, 1527 1529.

OAKLEY, A., STRANGE, V., BONELL, C., ALLEN, E., STEPHENSON, J. \& AND THE RIPPLE STUDY TEAM 2006. Process evaluation in randomised controlled trials of complex interventions. British Medical Journal, 332, 413 416.

OXMAN, A., LAVIS, J. N., LEWIN, S. \& FRETHEIM, A. 2009. SUPPORT Tools for Evidence-Informed Health Policymaking (STP) 1: What is evidence-informed policymaking? Health Research Policy and Systems, 7, S1.

PABLOS-MENDEZ, A. \& SHADEMANI, R. 2006. Knowledge Translation in Global Health. The Journal of Continuing Education in the Health Professions, 26, 81 -86 .

RITCHIE, J. \& SPENCER, L. 1994. Qualitative Data Analysis for Applied Policy Research. In: BRYMAN, A. \& BURGESS, R. G. (eds.) Analyzing Qualitative Data. London: Routledge.

RYCHETNIK, L., FROMMER, M., HAWE, P. \& SHIELL, A. 2002. Criteria for Evaluating Evidence on Public Health Interventions. Journal of Epidemiology and Community Health, 56, 119 - 127.

RYCHETNIK, L., HAWE, P., WATERS, E., BARRATT, A. \& FROMMER, M. 2004. A Glossary for Evidence Based Public Health. Journal of Epidemiology and Community Health, 58, 538-545.

SANSON-FISHER, R. W., BONEVSKI, B., GREEN, L. W. \& D'ESTE, C. 2007. Limitations of the Randomized Controlled Trial in Evaluating PopulationBased Health Interventions. American Journal of Preventive Medicine, 33, $155-161$.

SHELDON, T. A. 2005. Making Evidence Synthesis More Useful for Management and Policy-Making. Journal of Health Services Research and Policy, 101 - 5.

SIDDIQI, K. \& NEWELL, J. N. 2005. Putting Evidence into Practice in Low-Resource Settings. Bulletin of the World Health Organisation, 83, 882.

TOMSON, G., PAPHASSARANG, C., JONSSON, K., HOUAMBOUN, K., AKKHAVONG, K. \& WAHLSTROM, R. 2005. Decision-Makers and the Usefulness of Research Evidence in Policy Implementation - A case study from Lao PDR. Social Science and Medicine, 61, 1291 - 1299 
VICTORA, C. G., HABICHT, J.-P. \& BRYCE, J. 2004. Evidence-Based Public Health: Moving beyond randomized trials. American Journal of Public Health, 94, 400 - 405.

WATERS, E. 2009. Evidence for public health decision-making: towards reliable synthesis. Bulletin of the World Health Organisation, 87, 164.

WIGGINS, M., BONELL, C. \& BURCHETT, H. E. 2006. Evaluating Health Promotion. In: MACDOWALL, W., BONELL, C. \& DAVIES, M. (eds.) Health Promotion Practice: Understanding Public Health. Maidenhead: Open University Press.

WOELK, G., DANIELS, K., CLIFF, J., LEWIN, S., SEVENE, E., FERNANDES, B., MARIANO, A., MATINHURE, S., OXMAN, A. D., LAVIS, J. N. \& LUNDBORG, C. S. 2009. Translating Research into Policy: Lessons learned from eclampsia treatment and malaria control in three southern African countries. Health Research Policy and Systems, 7, 31.

WORLD HEALTH ORGANIZATION. 2010. Global Health Observatory [Online]. Available: http://www.who.int/gho/countries/en/index.html\#G [Accessed 7th May 2010. 